\title{
A DELIMITAÇÃO POLITICO-ADMINISTRATIVA DOS BAIRROS DO MUNICÍPIO DE URUSSANGA, SANTA CATARINA, BRASIL
}

\section{THE POLITICAL-ADMINISTRATIVE DELIMITATION OF DISTRICTS IN URUSSANGA, SANTA CATARINA, BRAZIL}

\footnotetext{
Augusto Sorato

Engenheiro Agrimensor. E-mail:

augusto.sorato@hotmail.com

Nilzo Ivo Ladwig

Professor do Programa de

Pós-graduação em Ciências

Ambientais - PPGCA - Unesc.

E-mail: ladwig@unesc.net

Danrlei De Conto

Mestrando no Programa de Pós-graduação em Ciências Ambientais - PPGCA/ Unesc. E-mail:

danrleideconto@hotmail.com

Ana Paula Cittadin

Mestranda no Programa de Pós-graduação em Ciências Ambientais - PPGCA/ Unesc. E-mail:

paulacittadin@hotmail.com
}

\section{Resumo}

A delimitação político-administrativa do território gera benefícios diretos e indiretos tanto para a população, como também para os administradores públicos, orientando ações de planejamento e gestão territorial, bem como políticas públicas. Com o intuito de ajudar o poder público municipal, este trabalho tem como objetivo propor uma delimitação político-administrativa de todos os bairros do município de Urussanga localizado na região sul do Estado de Santa Catarina. Para alcançar o objetivo utilizou-se de pesquisa documental e bibliográfica para desenvolver a proposta do mapa de divisão político-administrativa. Esta delimitação foi baseada em conceitos, percepção dos moradores, aspectos físicos e naturais como limites entre bairros. Durante a construção da proposta de divisão territorial para os limites dos bairros do município percebeu-se que havia uma certa inconsistência na demarcação existente, atrelada a vínculos ligados à formação histórica territorial do município, podendo assim, acarretar em um planejamento equivocado por parte dos gestores municipais. $\mathrm{O}$ mapeamento resultou na amarração cartográfica de cinquenta e um (51) bairros. A validação desta proposta do mapa político-administrativo por meio de legislação municipal será um avanço na elaboração do plano municipal de desenvolvimento de bairros.

Palavras-chave: Cartografia, Território, Município, Legislação

\begin{abstract}
The political-administrative delimitation of the territory generates direct and indirect benefits for both the population and public administrators, guiding actions of planning and territorial management, as well as public policies. In order to help the municipal government, this work aims to propose a political-administrative delimitation of all districts that are part of the municipality of Urussanga located in the southern region of the State of Santa Catarina. To achieve the objective, documentary and bibliographic research was used to develop the proposal for the political-administrative division map. This delimitation was based on concepts, perception of residents, physical and natural aspects as boundaries between districts. During the construction of the proposal for territorial division for the limits of the districts of the municipality, it was noticed that there was a certain inconsistency in the existing demarcation, linked to links linked to the territorial historical formation of the municipality, thus being able to result in a wrong planning by the managers municipal. The mapping resulted in fifty-one (51) districts. The validation of this proposal of the political-
\end{abstract}


Revista Tecnologia e Ambiente, v. 27, 2021, Criciúma, Santa Catarina/SC - ISSN Eletrônico 2358-9426 e ISSN Impresso 1413-8131

administrative map through municipal legislation will be an advance in the elaboration of the municipal district development plan.

Keywords: Cartography, Territory, Municipality, Legislation 


\section{Introdução}

Para compreender o contexto histórico de formação territorial do município de Urussanga, é necessário voltar ao passado. A Itália passava no final da década de 1840 por uma crise dolorosa que se estendeu até a década de 1870, em que as altas taxas e impostos atingiam a população menos favorecida, a agricultura era explorada por feudatários e o pequeno lavrador era incapaz de se sustentar e sustentar sua família por meio da agricultura (MARZANO, 1985).

Deste modo, o governo imperial brasileiro estimulava a imigração por meio de impulsos, oferecendo trabalho assalariado e terras para colonizar com a promessa de uma nova vida. Com o governo contribuindo, a emigração se disseminou por todos os vales, vilas e recantos do norte italiano (TONETTO; GHIZZO; PIROLA, 2015).

Em 19 janeiro de 1867, o governo brasileiro lançou o decreto $n^{\circ} 3.784$, que aprovava e regulamentava a implantação das colônias no Brasil, fomentando ainda mais a imigração e garantindo aos colonos as portas do Brasil. (TONETTO; GHIZZO; PIROLA, 2015).

Nos anos de 1876 a 1878, circulares, jornais e conferencistas comunicavam aos cidadãos europeus apontando a América como terra prometida, de modo a incentivar a emigração, em particular para o Brasil (MARZANO, 1985).

Em 1876 foi designada pelo ministro da agricultura da época uma comissão de engenheiros, comandado pelo Dr. Joaquim Vieira Ferreira, para examinar as terras devolutas localizadas mais ao sul do vale de Tubarão e Urussanga e escolher o melhor local para sediar a nova colônia e dispor da organização dos lotes baseados nas plantas da comissão do engenheiro Sampaio. Em abril do ano de 1877, chegaram os primeiros imigrantes responsáveis por colonizar as terras situadas mais ao sul do vale do rio Tubarão, a denominada colônia de Azambuja, por meio de longas caminhadas mediante abertura de picadas na mata (TONETTO; GHIZZO; PIROLA, 2015).

Com a colônia de Azambuja prosperando, em 26 de maio de 1878 foi povoado o primeiro núcleo da colônia, Urussanga, local este que mais tarde se tornaria o principal polo da imigração italiana no sul do Estado de Santa Catarina (TONETTO; GHIZZO; PIROLA, 2015).

A ocupação dos lotes coloniais de Urussanga criou topônimos para algumas partes da colônia. Estes topônimos foram os primeiros nomes dados ao local onde uma 
determinada população residia, quase sempre de um santo homenageado ou do rio que banhava os lotes.

O êxodo rural iniciou durante a segunda metade do século XIX e se intensificou na terceira revolução industrial (metade do século XX), contribuiu para que novos bairros nos núcleos urbanos surgissem no município de Urussanga. Em nenhum momento da história os limites dos bairros de Urussanga foram definidos, de forma que a inconsistência sobre a delimitação destes espaços permanece até hoje. Assim, para contribuir e minimizar o conflito dos limites dos bairros foi traçado o objetivo deste estudo que consistiu em propor uma delimitação político-administrativa do território do município de Urussanga localizado na região sul do Estado de Santa Catarina, considerando que existem cinquenta e um (51) bairros no município de Urussanga.

\section{Material e Métodos}

2.1 Localização e caracterização da área de estudo

Localizado na região sul do Brasil e no sul do estado de Santa Catarina, o município de Urussanga faz parte da microrregião de Criciúma e integra a Associação dos Municípios da Região Carbonífera (AMREC). A área de estudo compreende os limites geográficos entre as coordenadas $28^{\circ} 07^{\prime} 33^{\prime \prime}$ 'Sul e $49^{\circ} 33^{\prime} 11^{\prime}$ ' Oeste e $28^{\circ} 26^{\prime}$ 20', Sul e 49 11'22', Oeste (Figura 1).

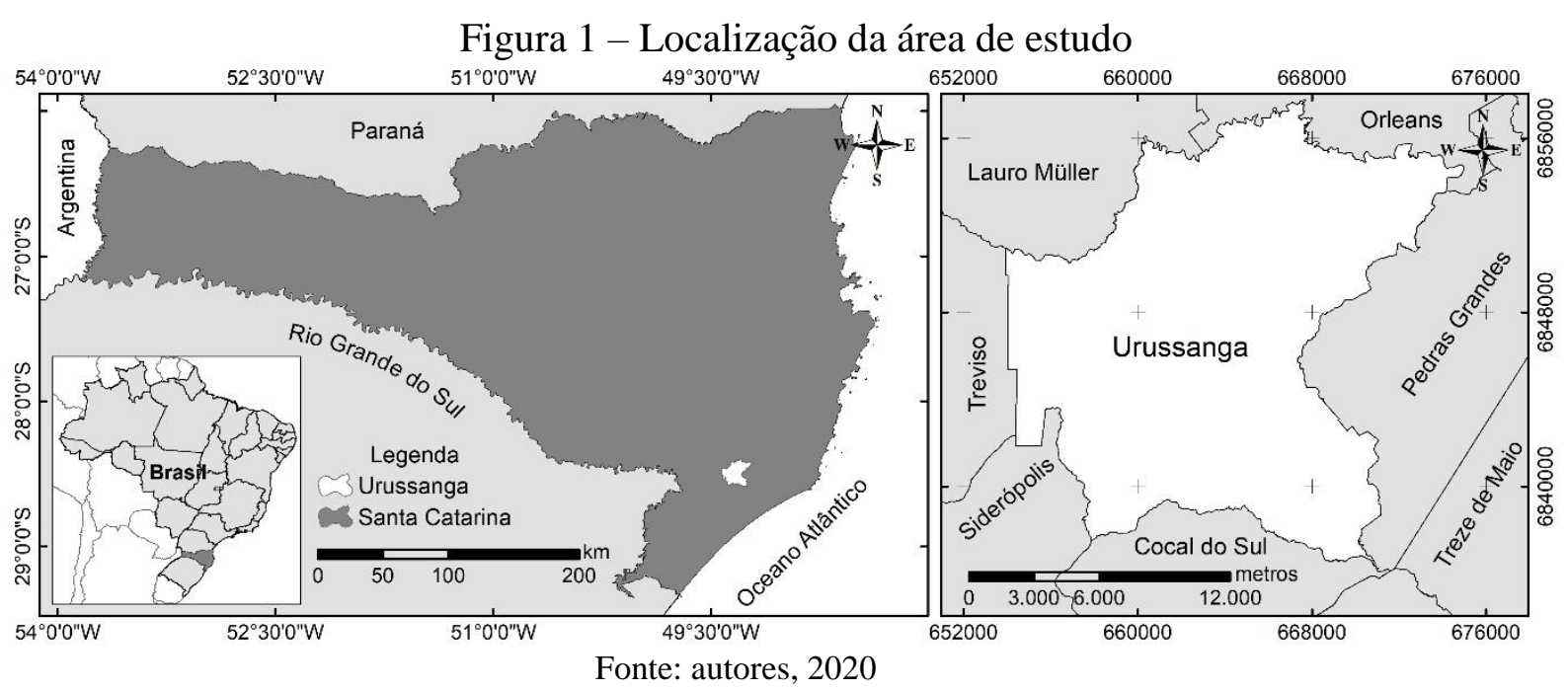

O município de Urussanga possui uma área territorial de 254,9 km² (IBGE, 2018).

Relevo predominantemente acidentado, havendo cerca de $30 \%$ de terrenos planos ondulados e $70 \%$ de área com declividade acima de $20 \%$, estando a uma altitude de 
aproximadamente 49 metros acima do nível do mar, com predomínio de solo podzólico e com um clima considerado subtropical úmido (URUSSANGA, 2019).

O principal acesso ao município é por meio da rodovia SC-108 (antiga SC-446), que liga os municípios de Criciúma e Orleans, e por meio da SC-445 que liga os municípios de Urussanga e Morro da Fumaça à BR-101.

O fluxograma a seguir mostra o caminho metodológico para a delimitação político-administrativa dos bairros.

Figura 2 - Fluxograma de trabalho

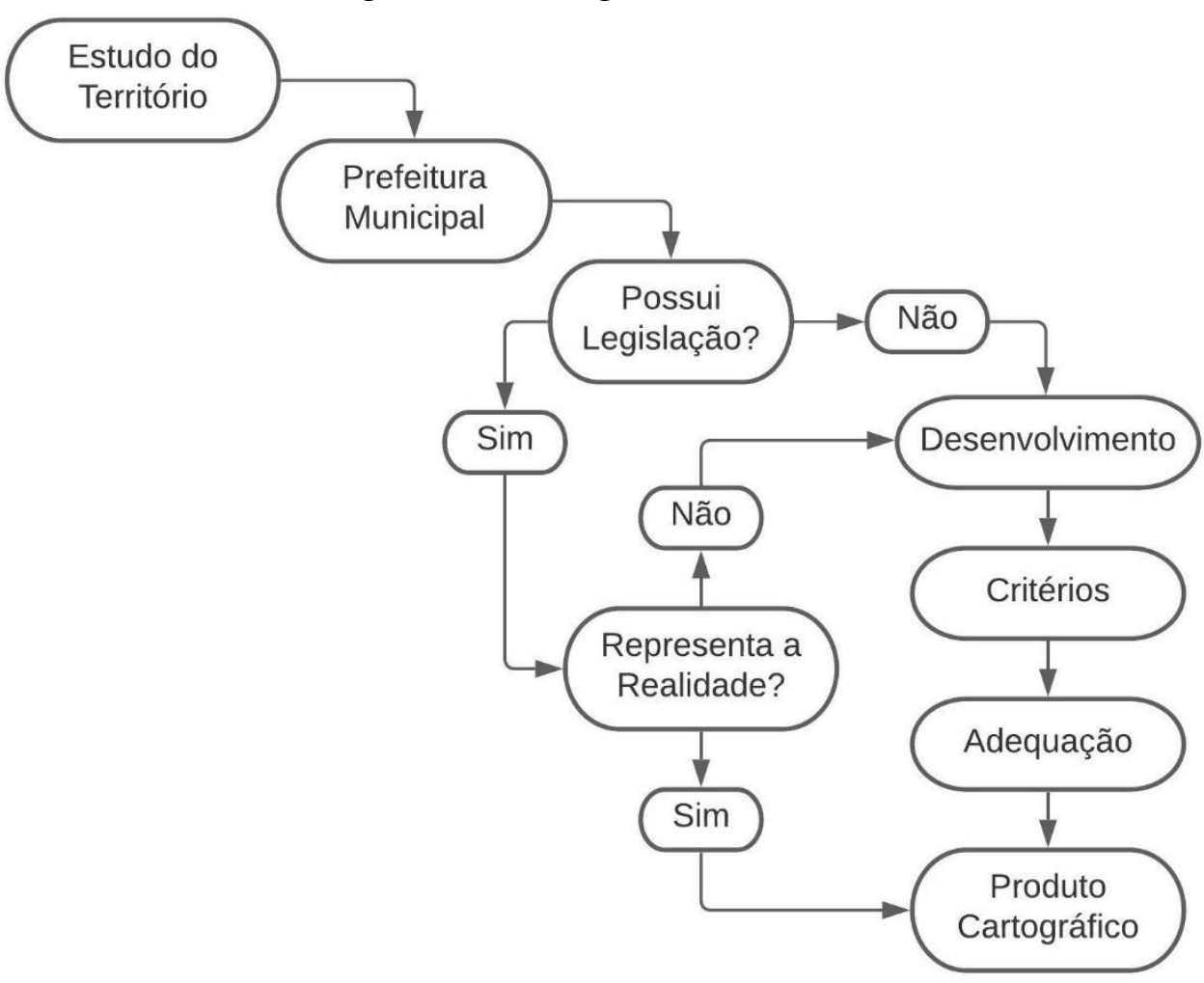

Fonte: autores, 2020

\subsection{Metodologia}

A elaboração do mapa da divisão político-administrativa contou com o auxílio dos delimitadores físicos, sendo eles estradas, parques, loteamentos, divisão colonial do mapa da colonização datado de 1878, ferrovias e rede elétrica. Já os delimitadores naturais são os rios, as linhas divisoras de água e outros elementos de ordem geomorfológica.

Na elaboração e na delimitação da proposta de divisão político-administrativa dos bairros de Urussanga foi utilizada ainda a orientação de Cazollato (2005), que definiu critérios e procedimentos metodológicos que podem ser utilizados na construção de uma definição padrão do território de bairro. 
O autor citado utilizou o nível de escala ou nível hierárquico: origem, extensão, delimitação, denominação, áreas de usos especiais e população para determinação padrão do bairro. Nesta pesquisa foram utilizados apenas alguns dos critérios de Cazollato (2005) que melhor se adequaram ao município de Urussanga, somados a outros critérios considerados importantes pelos autores.
a) Origem
b) Delimitação
c) Denominação
d) Áreas de uso especiais
e) População
f) Cadastro Ambiental Rural - CAR
g) Mapa da Colonização de 1878
h) Bacia Hidrográfica

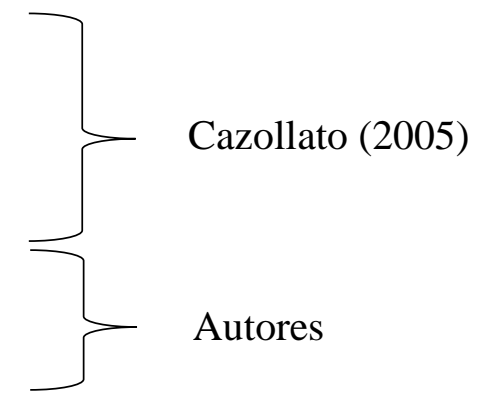

Ainda assim, há locais nos quais não foi possível utilizar nenhum dos critérios mencionados acima, sendo necessário a utilização de pontos de amarração para definir o limite do bairro nesses casos especiais.

Utilizando-se destes critérios, de uma base de dados estruturada em ambiente de Sistema de Informação Geográfica (SIG) e considerando cada bairro como único, a divisão político-administrativa do município de Urussanga foi traçada. Esse procedimento foi realizado com o auxílio do software ArcGIS 10.3.1, por meio do qual foi possível delimitar cada bairro, bem como calcular sua área.

\section{Resultados e Discussão}

3.1 Análise da legislação municipal considerando a delimitação dos bairros no perímetro urbano e rural

O município de Urussanga possui um total de cinquenta e um (51) bairros distribuídos no território do município, sendo que, dentro do perímetro urbano central estão localizados dezesseis (16) bairros. O restante trinta e cinco (35) ocupam o espaço rural. Deste total apenas 3 bairros possuem a sua criação definida em lei.

Quadro 1 - Bairros pertencentes ao perímetro urbano central com legislação de criação

\begin{tabular}{|l|l|}
\hline Bel Recanto & LEI N $^{\circ} 817$, de 27 de outubro de 1981 \\
\hline Bela Vista & LEI N $^{\circ} 1178$, de 13 de março de 1990 \\
\hline De Brida & LEI N $^{\circ} 544$, de 30 de junho de 1976 \\
\hline
\end{tabular}

Fonte: Prefeitura Municipal de Urussanga, 2020 
Dois (2) dos três (3) bairros que possuem legislação, quando verificado seus limites descritos na lei com a realidade atual de ocupação percebe-se que existem inconsistências no reconhecimento dos limites por parte da comunidade. O bairro Bel Recanto continua com a mesma configuração espacial de quando foi criado, já os bairros De Brida e Bela Vista se modificaram, de modo que se faz necessário a alteração na legislação destes bairros para que represente a realidade da ocupação do espaço.

Essa inconsistência está atrelada ao crescimento urbano de bairros vizinhos ou o crescimento do próprio bairro em questão. O bairro Bela Vista é um exemplo de expansão, em sua criação era formado por três loteamentos, hoje o bairro está maior e a sua legislação continua a mesma. A expansão do bairro Bela Vista é representada na Figura 3 demonstrando o conflito da legislação com a realidade territorial de ocupação.

Já no bairro De Brida (figura 3b) a expansão espacial dos bairros vizinhos fez com que o bairro diminuísse de área, a explicação está atrelada as condições de relevo íngreme que limita a ocupação urbana.

Figura 3 - Conflitos legislação x realidade espacial do bairro Bela Vista e De Brida

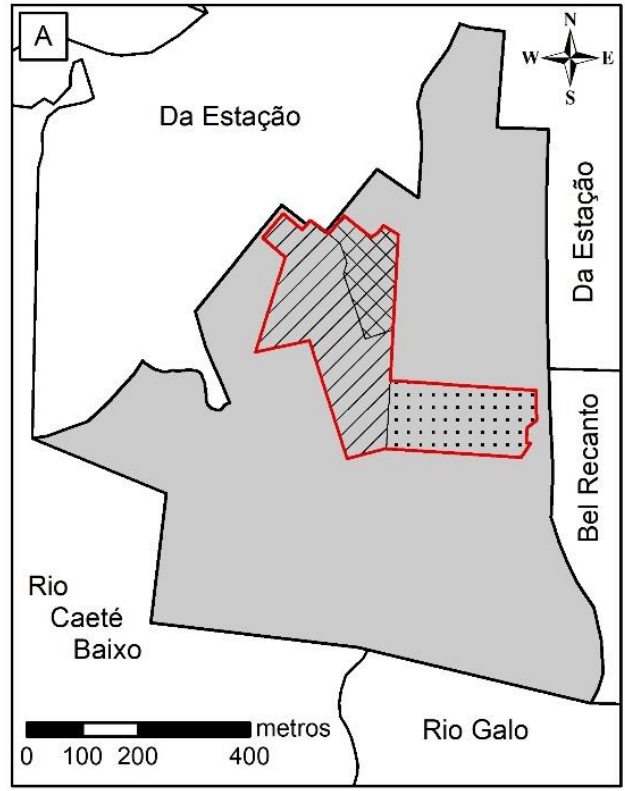

Legenda

3 Limites Políticos

$\widetilde{ }$ Bairro Bela Vista

C Bairro Bela Vista (Lei)

Loteamentos

$\nabla \backslash$ Bela Vista

X Boa Vista

::: Jardim Eldorado

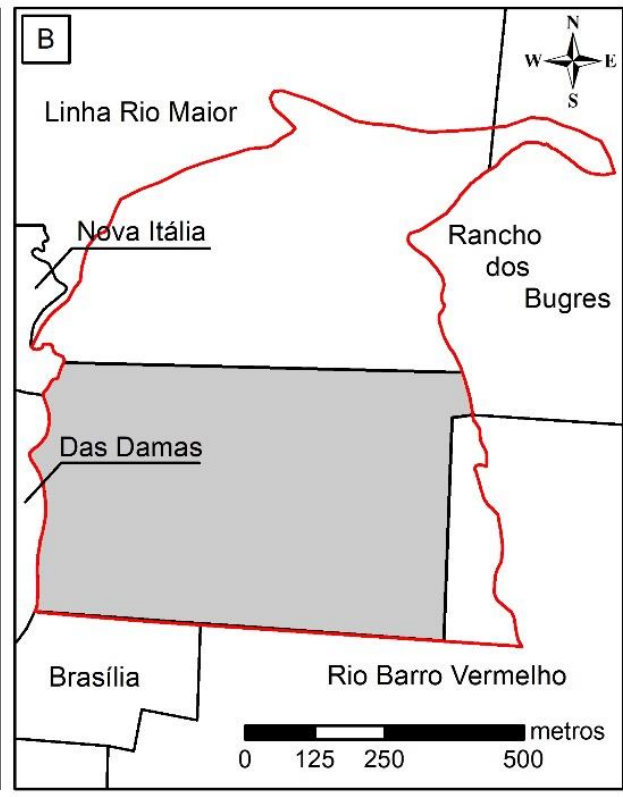

Legenda

C Bairro De Brida (Lei)

3 Limites Políticos

C Bairro De Brida

Fonte: autores, 2020 
Percebe-se que o bairro Bela Vista avançou sobre o espaço dos bairros vizinhos, multiplicando em mais de seis vezes seu tamanho, porém sua legislação continua a mesma de sua criação. Ao analisar o bairro De Brida nota-se que o mesmo teve sua área diminuída pelo crescimento dos bairros denominados como Linha Rio Maior e Rio Barro Vermelho. Em ambos os casos a alteração da legislação é necessária para que represente a realidade espacial destes bairros.

\subsection{Critérios considerados na divisão do município em bairros}

Seguindo os critérios de como definir um bairro proposto por Cazollato (2005), adequando-os para o município de Urussanga e inserindo novos critérios, percebeu-se que para construir o mosaico dos bairros não existe uma orientação cartográfica definida, de modo que se faz necessário adequar cartograficamente um a um da melhor forma.

Os critérios utilizados foram:

Origem - considerar a história sobre a formação do bairro, podendo ter sido oriunda da união de um ou mais loteamentos, ou a pela formação espontânea da ocupação. Vale ressaltar que, mesmo sendo composto na maioria das vezes por loteamento, a divisão dos bairros não se atém ao parcelamento do solo. Urussanga, por sua vez, é formada basicamente pela divisão colonial explicada anteriormente, ou seja, a formação da área tanto rural e urbana está atrelada a este parcelamento histórico. Na parte urbana, poucos são os bairros que foram criados por meio de uma lei específica. O bairro Bela Vista é um exemplo de enquadramento neste item, sendo formado por três loteamentos redigidos em lei.

Delimitação - os elementos visuais são certamente de fácil percepção, sendo considerados na memorização pela população. As vias existentes, recursos hídricos, rede ferroviária, rede elétrica de alta tensão, parques, bacias hidrográficas e outros são exemplos desse indicador. Na maioria das vezes, os bairros são divididos por alguma ruptura, podendo ser um limite físico construído ou mesmo natural. Este indicador é um dos itens com maior influência para a delimitação dos bairros no Munícipio de Urussanga, sendo utilizado constantemente neste trabalho. Um exemplo claro é o bairro Nova Itália, delimitado basicamente pelo rio Carvão e pelo rio Maior.

Denominação - para que haja uma melhor organização do território, os logradouros deveriam começar em um bairro e terminar em outro. Os topônimos, ou seja, 
os nomes das vias, igrejas e centros comunitários, são de forte influência para denominação dos bairros. Em Urussanga, essa denominação não está associada ao seccionamento das ruas, ou seja, a continuidade dos logradouros é característica do município. Já os topônimos que denominam os bairros são de forte influência e estão amarrados a alguma característica histórica, geográfica ou arqueológica do bairro. Podese citar os bairros da Estação, Morro da Gloria, Baixada Fluminense, Das Damas, Vila São José, De Brida, entre outros.

Áreas de usos especiais - utilizado como limitador de utilização de áreas em comum pela sociedade como: parques, terminais de transporte, áreas protegidas, entre outros equipamentos. O município de Urussanga possui um parque municipal e uma Área de Proteção Ambiental (APA), considerados pela prefeitura como delimitadores de bairros. A APA está dentro de 3 bairros, sendo Linha Rio Maior, Rio Maior e São João do Rio Maior pertencentes às áreas rurais do município.

População - consiste em buscar uma equidade social perante a população. Sabese dos desafios de se implementar obras no município quando se trata de um lugar que possui territórios populosos e outros com menor população. Em Urussanga podemos citar o bairro São Pedro, um dos bairros mais antigos do município, o qual possui uma população inferior ao bairro De Villa. Assim, podemos dizer que em Urussanga os bairros com menor densidade populacional são subordinados a bairros com maiores densidades, fato este que pode ser utilizado para buscar uma delimitação mais justa e igualitária para bairros com menor densidade.

Cadastro Ambiental Rural (CAR) - com o auxílio do CAR em arquivo vetorial foi possível visualizar a espacialização dos imóveis rurais no município de Urussanga. Mesmo não sendo um documento cartográfico consistente, o CAR fornece uma visão espacial aproximada das linhas divisórias dos imóveis, permitindo observar e comparar as linhas divisórias atribuídas pela população como divisor de bairros em alguns casos.

Mapa colonial de 1878 - Os alinhamentos, também chamados de "travessões", são o final do lote colonial, que podem ser estendidos por quilômetros, delimitando, assim, não só a divisão de propriedade, mas também a divisa de bairros em alguns casos. Por meio do CAR foram observados os alinhamentos contidos no mapa da colonização, sendo que em alguns bairros, como Armazém, Santana, Rio Maior e outros foi possível perceber esse alinhamento, bem como utiliza-los como divisa de bairro. 
Bacias hidrográficas - são elementos naturais da paisagem responsáveis por representar a configuração natural dos elementos de drenagem. O divisor de águas de uma bacia pode ser atribuído como um delimitador de bairro, já que o mesmo representa a contribuição dos afluentes até a chegada a um afluente principal. Em Urussanga, geralmente, este afluente principal possui o nome de um bairro como, Rio Deserto, no qual uma parte da bacia do Rio Deserto delimita o bairro.

Ponto de amarração - utilizado em último caso onde não foi possível definir um limite adequado conforme a realidade do bairro ou em casos específicos que não se tem nenhum elemento disponível para poder defini-lo. Os pontos de amarração foram criados sobre o limite administrativo entre municípios. Como exemplo, pode-se citar os bairros Belvedere Baixo e São Donato.

\subsection{A divisão político-administrativa municipal}

Com a aplicação dos critérios e analisando cada bairro como sendo único a divisão político-administrativa proposta é semelhante à divisão que se tem hoje in loco, porém, quando atribuída ao senso comum dos moradores certamente haverá interpretação, por vezes, diferente dos limites dos quais o bairro está inserido, os moradores quando questionados relatam o seu entendimento de divisa do bairro.

Assim, se faz necessária a adequação participativa da unidade territorial para que a mesma satisfaça a maioria das percepções, tendo ainda uma divisão a qual possa ser identificada claramente.

Percebe-se que a maioria dos bairros de Urussanga possuem predominância de topônimos padrão conforme discutido, podendo ser de santos religiosos, como os bairros São Pedro, São Valentim, São Donato e Santa Luzia, e de rios como os bairros Rio Maior, Rio Deserto, Rio Comprudente e Rio Salto. Alguns bairros utilizam o relevo para representar lugares como alto e baixo, como os bairros Palmeira Alta, Palmeira do Meio e Palmeira Baixa, e ainda em alguns casos são utilizados dois topônimos, como os bairros Rio Carvão, Rio Carvão Alto e Rio Carvão Baixo.

Desta forma a proposta de definição dos limites territoriais de cinquenta e um (51) bairros do município de Urussanga foram traçados e estão representados no mapa (Figura 4). 
Pode-se observar na Figura que os bairros do município de Urussanga não possuem um formato padrão. Essa conformação espacial não se deve unicamente à metodologia utilizada, mas também pelo senso de pertencimento da população. A Tabela 1 mostra a nomenclatura de todos os bairros do município de Urussanga e suas respectivas áreas.

Figura 4- Mapa da divisão político-administrativa do município de Urussanga

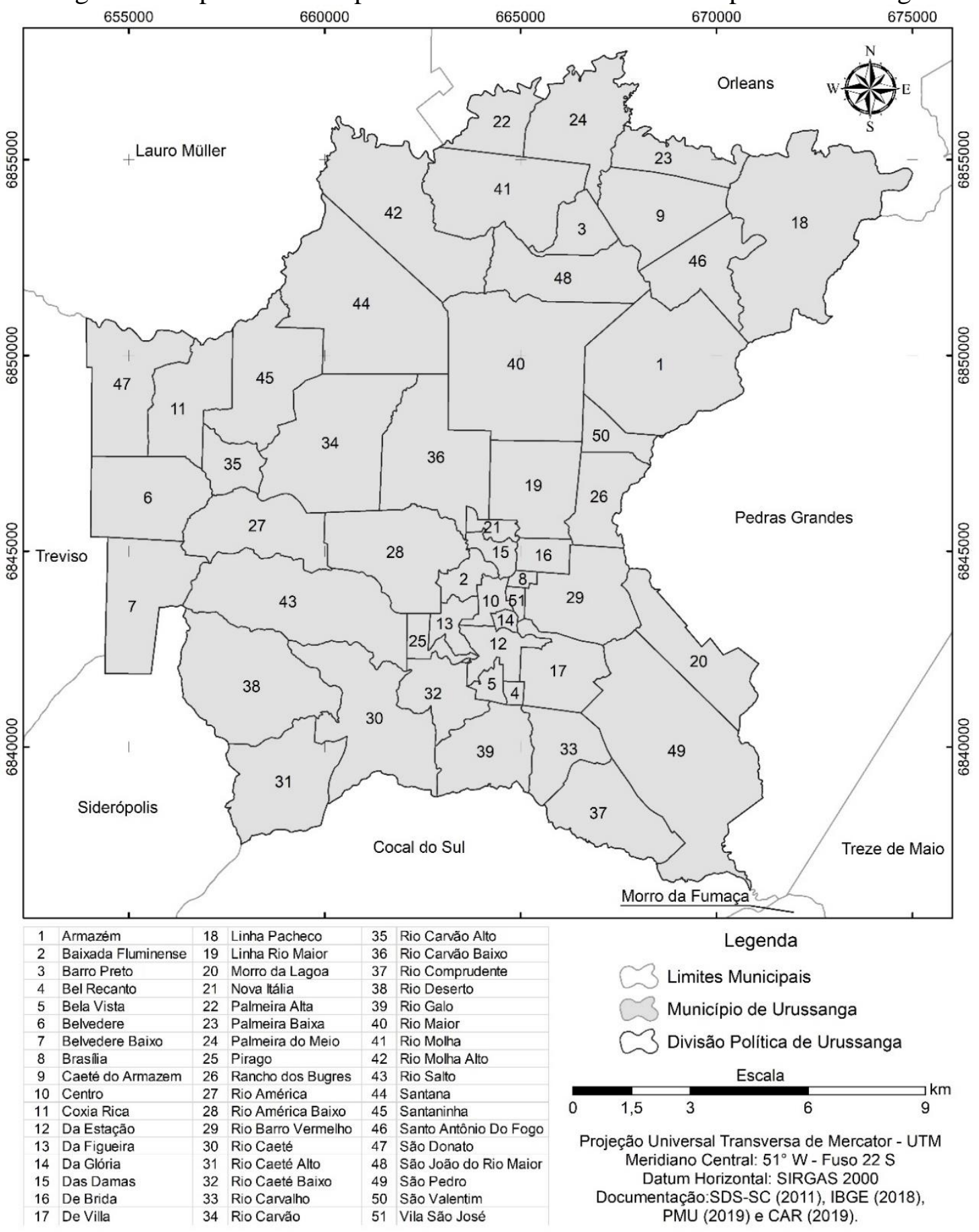

Obs.: O mapa pode ser encontrado em apêndice em uma escala que facilita a sua leitura.

Fonte: autores, 2020 
Tabela 1 - Bairros e suas respectivas áreas

\begin{tabular}{|c|c|c|c|c|c|}
\hline $\mathbf{N}^{\mathbf{o}}$ & Nomenclatura do Bairro & $\begin{array}{c}\text { Área } \\
\text { km }^{2}\end{array}$ & $\mathbf{N}^{\mathbf{o}}$ & Nomenclatura do Bairro & $\begin{array}{c}\text { Área } \\
\text { km }^{2}\end{array}$ \\
\hline 1 & Armazém & 10,961 & 27 & Rio América & 5,290 \\
\hline 2 & Baixada Fluminense & 1,133 & 28 & Rio América Baixo & 6,84 \\
\hline 3 & Barro Preto & 1,957 & 29 & Rio Barro Vermelho & 5,297 \\
\hline 4 & Bel Recanto & 0,293 & 30 & Rio Caeté & 8,243 \\
\hline 5 & Bela Vista & 0,623 & 31 & Rio Caeté Alto & 6,333 \\
\hline 6 & Belvedere & 5,773 & 32 & Rio Caeté Baixo & 2,993 \\
\hline 7 & Belvedere Baixo & 5,889 & 33 & Rio Carvalho & 3,212 \\
\hline 8 & Brasília & 0,270 & 34 & Rio Carvão & 9,707 \\
\hline 9 & Caeté do Armazém & 5,435 & 35 & Rio Carvão Alto & 1,931 \\
\hline 10 & Centro & 0,884 & 36 & Rio Carvão Baixo & 7,639 \\
\hline 11 & Coxia Rica & 4,791 & 37 & Rio Comprudente & 5,156 \\
\hline 12 & Da Estação & 1,825 & 38 & Rio Deserto & 9,169 \\
\hline 13 & Da Figueira & 1,183 & 39 & Rio Galo & 4,459 \\
\hline 14 & Da Glória & 0,289 & 40 & Rio Maior & 13,198 \\
\hline 15 & Das Damas & 0,849 & 41 & Rio Molha & 7,598 \\
\hline 16 & De Brida & 1,176 & 42 & Rio Molha Alto & 9,321 \\
\hline 17 & De Villa & 3,724 & 43 & Rio Salto & 9,853 \\
\hline 18 & Linha Pacheco & 13,97 & 44 & Santana & 12,286 \\
\hline 19 & Linha Rio Maior & 5,163 & 45 & Santaninha & 6,53 \\
\hline 20 & Morro da Lagoa & 4,838 & 46 & São Antônio do Fogo & 4,247 \\
\hline 21 & Nova Itália & 0,666 & 47 & São Donato & 5,913 \\
\hline 22 & Palmeira Alta & 2,716 & 48 & São João do Rio Maior & 5,288 \\
\hline 23 & Palmeira Baixa & 2,950 & 49 & São Pedro & 15,3 \\
\hline 24 & Palmeira do Meio & 5,671 & 50 & São Valentim & 1,575 \\
\hline 25 & Pirago & 0,985 & 51 & Vila São José & 0,306 \\
\hline 26 & Rancho dos Bugres & 3,221 & & TOTAL & 254,959 \\
\hline
\end{tabular}

O município de Urussanga possui bairros que variam entre 15,3 a 0,27 $\mathrm{km}^{2}$. Considerando a proposta, o maior bairro em área é o bairro São Pedro, pertencente em parte à área urbana. O menor é o bairro Vila Brasília, localizado na área urbana.

Nota-se com o auxílio do mapa que os menores bairros são os que estão localizados dentro da cidade de forma que delimitam a malha urbana, e que os bairros rurais formam a maior parte do território do município.

Com a construção da proposta cartográfica, é importante não só identificar os limites conforme metodologia, mas também descrevê-los para fins de formulação de uma legislação mais contundente.

\section{CONSIDERAÇÕES FINAIS}


Os resultados demonstraram que a delimitação político-administrativa de bairros em um município é importante ao planejamento municipal. Conclui-se que o município de Urussanga carece de informações sobre a atual delimitação político-administrativa, tendo em vista o seu crescimento na ocupação espacial ter se dado de forma desordenada e sem planejamento.

De acordo com a pesquisa, apenas três bairros possuem legislação sobre a sua criação e delimitação de seus limites, sendo que, em função da data de aprovação da lei, a maioria dos limites já sofreram algum tipo alteração ou não representam mais a realidade do bairro, resultando, assim, na necessidade de uma nova delimitação.

Buscou-se, então, adequar não só os três bairros que já possuíam uma legislação, mas também os demais bairros por carecerem de uma legislação. A divisão políticoadministrativa proposta vai além de uma simples divisão, ela leva em consideração todos os itens elencados para definir um bairro, resultando em um produto cartográfico bem próximo da realidade dos bairros urussanguenses.

A legislação que cria, denomina e delimita o bairro é extremamente importante para evolução territorial do município. Ela não está ligada somente ao sentimento cultural dos moradores, mas também ao desenvolvimento econômico e social do bairro.

A importância da legislação que regulamenta a divisão dos bairros vai além dos aspectos culturais. Assim, que uma determinada região é definida, o morador passa a adotar este espaço como referência territorial e é possível acompanhar e planejar indicadores para avaliar a sua evolução.

As definições dos limites dos bairros poderão auxiliar no planejamento e desenvolvimento do território municipal de forma mais eficaz, contribuindo assim, para uma gestão eficiente.

Ainda se observa que as menores áreas da proposta estão localizadas dentro do perímetro urbano, isso acontece pela definição dos topônimos, utilizados com frequência em anos anteriores para diferenciar o local de residência dos moradores do município. Assim, de um bairro grande vão se desmembrando bairros menores, com características e identidade particulares e com topônimos diferentes.

Vale ressaltar que o senso comum pode definir os limites dos bairros de forma diferente da proposta apresentada. Sugere-se uma apresentação, discussão e adequação se 
necessário dos limites da divisão político-administrativa com o uso da cartografia participativa.

\section{REFERENCIAS}

CAZOLLATO, J. D. Os bairros como instância territorial local - contribuição metodológica para o caso de São Paulo. 2005. 159 f. Dissertação (Mestrado) - Programa de Pós-Graduação em Geografia Humana, Departamento de Geografia, Universidade de São Paulo, São Paulo, 2005.

IBGE - INSTITUTO BRASILEIRO DE GEOGRAFIA E ESTATÍSTICA. Malhas digitais: Santa Catarina, 2018. Disponível em: $<$ https://www.ibge.gov.br/geociencias/downloads-geociencias.html>. Acesso em: 15 out. 2019.

MARZANO, L. Colonos e missionários italianos nas florestas do Brasil. Tradução Pe. João Leonir Dall'Alba. Florianópolis: Ed. da UFSC, 1985. 200p.

TONETTO, E. P.; GHIZZO, I.; PIROLA, L. Colônia Azambuja: a imigração italiana no sul de Santa Catarina. Florianópolis: Epagri, 2015, 211p.

URUSSANGA. Prefeitura Municipal. Geografia. Disponível em: <https://www.urussanga.sc.gov.br/cms/pagina/ver/codMapaItem/30103>. Acesso em: 8 out. 2019. 


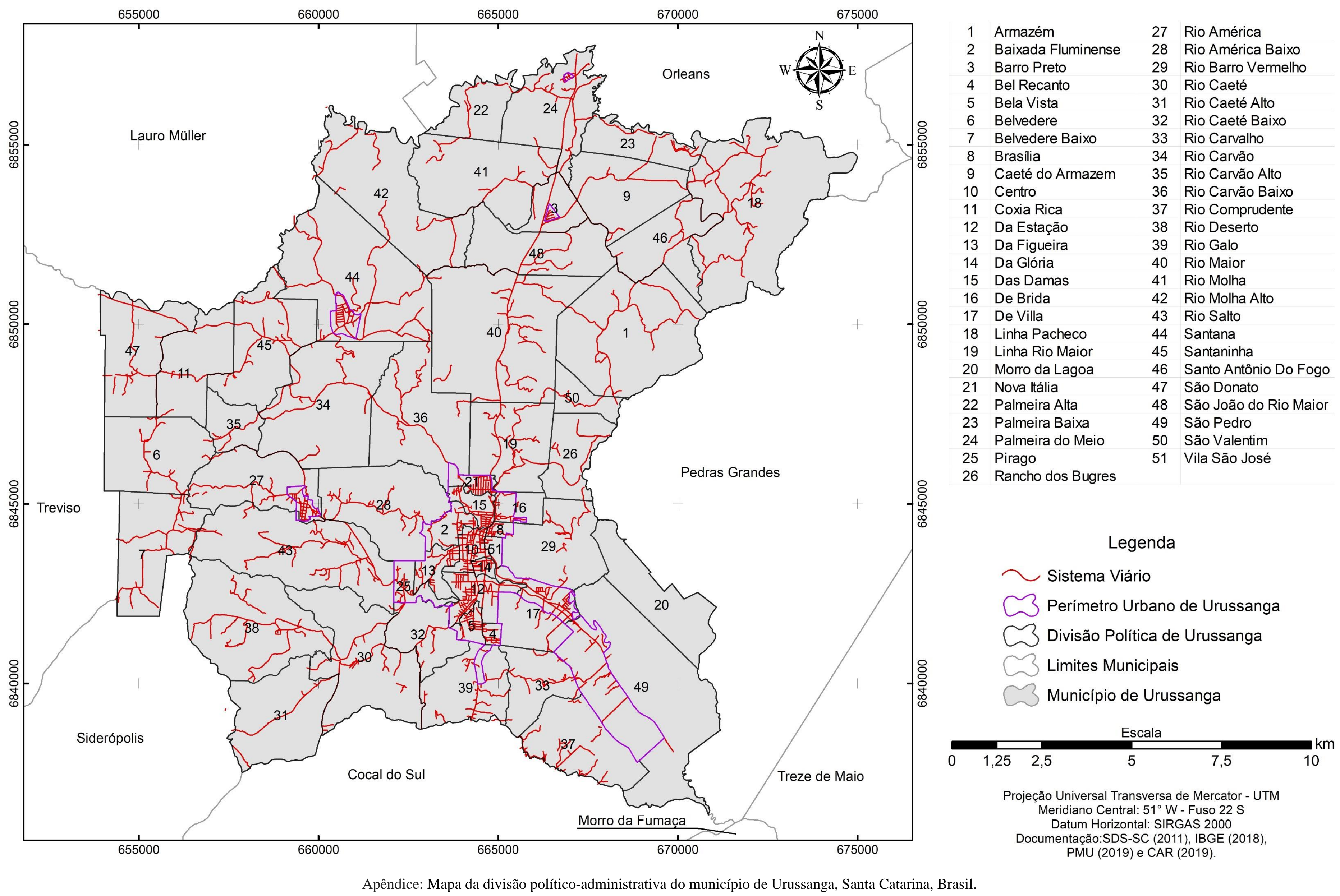

